\title{
INCORPORAÇÃO DE CARVÃO VEGETAL EM MISTURA DE CARVÕES PARA COQUEIFICAÇÃO EM FORNO PILOTO*
}

\author{
Daniel Rigon Orellana ${ }^{1}$ \\ Guilherme Liziero Ruggio da Silva ${ }^{2}$ \\ Ángeles Gómez Borrego ${ }^{3}$ \\ Antônio Cezar Faria Vilela ${ }^{4}$ \\ Eduardo Osório ${ }^{5}$
}

\section{Resumo}

O emprego de fontes renováveis de carbono encontra nos processos de coqueificação uma forma de reuso de partículas carbonosas finas ou fora das especificações necessárias para utilização em outros processos metalúrgicos, além de reduzir as emissões de carbono. O presente trabalho avalia os principais efeitos da incorporação de um carvão vegetal de eucalipto a uma mistura de carvões para a produção de coques em forno piloto. Para isso, o carvão vegetal foi adicionado em teores de $3 \%, 5 \%$ e $10 \%$, e em duas frações granulométricas, a uma mistura de carvões. A qualidade dos coques gerados foi avaliada e discutida ao longo do trabalho por ensaios de caracterização do coque como, análise imediata, teor de enxofre, reatividade e resistência pós-reação (CRI/CSR), resistência mecânica a frio (DI 150/15) e textura óptica. Foi observado que a adição de 3\% de carvão vegetal, na fração mais grosseira, à mistura de carvões resultou no coque de melhor qualidade.

Palavras-chave: Carvão vegetal; Coqueificação; Coque metalúrgico; Qualidade do coque.

\section{INCORPORATION OF CHARCOAL ON A METALLURGICAL COAL BLEND FOR COKEMAKING IN PILOT OVEN}

\section{Abstract}

The uses of renewable carbon sources finds on cokemaking process a way of reuse for fine carbonaceous particles or particles out of specifications for application into some other metallurgical process, in addition to reducing carbon dioxide emissions. The present work evaluates the main effects of incorporating a eucalyptus charcoal on a coal blend for coke production in pilot oven. For this purpose, the charcoal was added in contents of $3 \%, 5 \%$ and $10 \%$, in two different size fractions, to a coal blend. The quality of the produced cokes was evaluated and discussed through this work for coke characterization: proximate analysis, sulfur analysis, reactivity and strength after reaction (CRI/CSR), cold mechanical strength (DI 150/15) and optical texture. It was noticed that the $3 \%$ charcoal addition, with the coarser size fraction, resulted in the coke with the highest quality.

Keywords: Charcoal; Cokemaking; Metallurgical coke; Coke quality.

1 Engenheiro Metalúrgico, Aluno de Mestrado do PPGE3M, Universidade Federal do Rio Grande do Sul (UFRGS), Porto Alegre, RS, Brasil.

2 Engenheiro Metalúrgico, Aluno de Doutorado da REDEMAT, Universidade Federal de Ouro Preto, Ouro Preto, MG, Brasil.

3 Dra., Pesquisadora, Instituto Nacional del Carbón (INCAR), Oviedo, Espanha.

4 Dr-Ing, Professor, Coordenador do Laboratório de Siderurgia (LaSid), UFRGS, Porto Alegre, RS, Brasil.

5 Dr., Professor, Laboratório de Siderurgia (LaSid), UFRGS, Porto Alegre, RS, Brasil. 


\section{INTRODUÇÃO}

O Brasil, apesar de ter e de explorar algumas reservas de carvão mineral na Região Sul do país, é completamente dependente da importação de carvões metalúrgicos para consumo em coquerias, havendo importado em 2013 o equivalente a 11 milhões de toneladas [1]. A desaceleração da economia global e de grandes mercados consumidores como, China, Japão, Índia e Coréia do Sul, impactou fortemente na redução dos preços desse insumo nos últimos quatro anos. Contudo, espera-se que haja um aumento na demanda e os preços do mercado sejam afetados negativamente, atingindo os custos de produção do ferro-primário e a competitividade dos produtos da indústria brasileira do aço.

Uma alternativa para a redução de uma pequena parte das importações brasileiras de carvões coqueificáveis e também para o reaproveitamento de materiais carbonosos finos ou fora das especificações para uso em outros processos metalúrgicos é a utilização de carvão vegetal em misturas de carvões para a coqueificação. Essa questão já vem sendo discutida por diversos autores [2-7] e poderia trazer um reconhecimento ainda maior para o setor siderúrgico brasileiro, o qual já se destaca por gerar quase $10 \%$ de sua produção total de aço bruto através de altos-fornos a carvão vegetal e por contar com mais de 542 mil hectares de florestas plantadas e certificadas [8]. Além disso, o emprego de fontes renováveis de carbono, como biomassas cruas e carbonizadas, em processos siderúrgicos apresenta o benefício de reduzir as emissões de $\mathrm{CO}_{2}$ lançadas na atmosfera e fomentar a silvicultura nacional.

Todavia, a incorporação parcial de carvão vegetal em misturas de carvões, visando à fabricação de coques para grandes altos-fornos, deve atender a requisitos de qualidade em relação a especificações químicas e mecânicas. Dessa forma, o objetivo principal deste trabalho é avaliar as principais alterações causadas em coques produzidos com a adição de um carvão vegetal de eucalipto, agregado em duas frações granulométricas distintas, a uma mistura de carvões. Para isso, o carvão vegetal foi acrescentado à mistura em proporções de $3 \%, 5 \%$ e $10 \%$ para, mais tarde, serem carbonizados em forno piloto de coqueificação.

\section{MATERIAIS E MÉTODOS}

\subsection{Matérias-Primas}

Para este estudo, selecionaram-se uma mistura com carvões rotineiramente empregados em coquerias (MB) - composta por um carvão alto volátil americano $(30 \%)$, um carvão médio volátil canadense (35\%), um carvão baixo volátil americano (25\%) e coque de petróleo brasileiro (10\%) - e uma amostra de carvão vegetal de eucalipto proveniente do estado de Minas Gerais. Todos os componentes que constituíam a mistura foram coletados após o processo de britagem, possuindo granulometria $80 \%$ inferior a $2,83 \mathrm{~mm}$; enquanto o carvão vegetal utilizado foi distribuído em duas frações granulométricas: uma composta majoritariamente por partículas mais grosseiras (Fração G) e outra por partículas mais finas (Fração F). $O$ carvão vegetal passou por uma análise granulométrica em vibrador de peneiras durante 15 minutos, e com frequência de $12 \mathrm{~Hz}$, em peneiras com tamanho de abertura de 4,$0 ; 2,83 ; 1,4 ; 1,0$ e $0,5 \mathrm{~mm}$.

As matérias-primas foram caracterizadas quimicamente por análise imediata (ISO17426:2010), análise elementar (ISO-17247:2013) e análise de enxofre total (ISO- 
334:2013), em analisadores modelo TGA601, CHN-2000 e 144DR, respectivamente, no Instituto Nacional del Carbón (INCAR) - Espanha.

Uma análise de refletância da vitrinita em óleo em microscópio óptico, com base em 250 pontos, também foi realizada na mistura de carvões estudada, de acordo com a norma ISO 7404/5. A preparação da amostra para essa análise seguiu a norma ISO $7404 / 2$.

\subsection{Ensaios de Carbonização em Planta Piloto}

As frações $F$ e $G$ de carvão vegetal foram adicionadas individualmente à mistura de carvões MB para a elaboração de coques contendo teores mássicos de $3 \%, 5 \%$ e $10 \%$. Para isso, foi utilizado um forno elétrico resistivo de parede móvel com dimensões de $930 \mathrm{~mm}$ de comprimento, $450,5 \mathrm{~mm}$ de largura e $830 \mathrm{~mm}$ de altura.

Os ensaios de carbonização foram realizados durante 20 horas a $1100{ }^{\circ} \mathrm{C}$, utilizando uma carga de $130 \mathrm{~kg}$ de amostra (mistura base de carvões MB + \% de carvão vegetal) e resultando na produção de mais de $90 \mathrm{~kg}$ de coque. Todas as amostras foram introduzidas no forno com o mesmo preaquecido. Uma amostra composta somente pela mistura de carvões também foi gerada. Após a coqueificação, todos os coques foram extintos com água. A Figura 1 apresenta algumas das etapas do processo de produção dos coques, como a homogeneização das matérias-primas, o carregamento e também o descarregamento do forno de coqueificação. Esses ensaios foram feitos na unidade piloto da Gerdau, usina Ouro Branco.

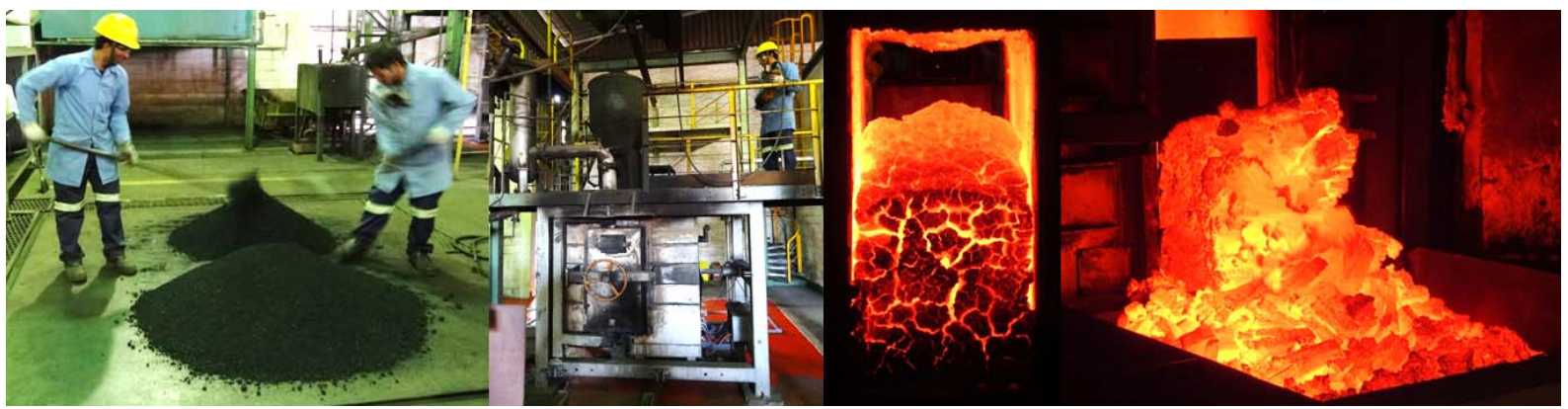

Figura 1. Etapas do processo de produção dos coques.

\subsection{Caracterização dos Coques}

Os coques elaborados com incorporação de carvão vegetal na fração granulométrica $F$ e na fração granulométrica $G$ foram denominados respectivamente como CF e CG, com o acréscimo de um número que representa o teor de carvão vegetal adicionado à mistura de carvões $M B$. Já o coque referência feito exclusivamente a partir da mistura base de carvões foi nomeado como CMB. A caracterização dos coques foi feita através de análise imediata, enxofre total, reatividade e resistência após reação (CRI/CSR - Coke Reactivity Index/Coke Strength After Reaction), resistência mecânica a frio e análise óptica. Tanto a análise imediata quanto a análise de determinação do teor de enxofre seguiram os procedimentos da norma ASTM D7582 e D4239.

Para a realização dos testes de reatividade (CRI) e resistência após reação (CSR), uma alíquota de aproximadamente $10 \mathrm{~kg}$ de coque, com granulometria entre $75 \mathrm{e}$ $25 \mathrm{~mm}$, foi preparada, britada e peneirada entre 19 e $22 \mathrm{~mm}$. O ensaio foi realizado segundo a norma ASTM D5341/D5341M. A resistência mecânica a frio dos coques 
produzidos foi determinada através de ensaio de tambor JIS 150/15, conhecido como DI (Drum Index), conforme a norma JIS K 2151.

As análises de microscopia óptica em microscópio de luz polarizada foram conduzidas no INCAR. Para tanto, amostras de coque com tamanho de partícula entre 19 e $22 \mathrm{~mm}$ foram cominuídas em um pistilo de aço até seus tamanhos de partícula serem reduzidos abaixo de $1 \mathrm{~mm}$. Uma quantidade de mais ou menos $10 \mathrm{~g}$ de cada coque foi misturada a uma resina epóxi para a elaboração dos corpos de prova a serem analisados. Toda a preparação foi executada de acordo com a norma ISO 7404/2. Um microscópio modelo DM 4500 P, foi empregado na determinação do volume percentual de componentes texturais no coque. As análises foram feitas com base em 500 pontos, imersão das amostras em óleo, e seguindo a norma ASTM D5061 para a classificação textural dos coques.

\section{RESULTADOS E DISCUSSÃO}

\subsection{Caracterização das Matérias-Primas}

A Tabela 1 apresenta os resultados de análise granulométrica feita em laboratório do carvão vegetal utilizado. A distribuição do tamanho de partícula de aditivos inertes é uma propriedade importante no processo de coqueificação, uma vez que ela influencia na densidade de carga da mistura [5] e, consequentemente, na resistência do coque. Isso se deve ao fato que durante a transformação do semicoque para coque, o semicoque e as partículas inertes apresentam diferentes coeficientes de contração. A tensão de contração maior do semicoque pode ser suportada e aliviada por partículas inertes menores $[9,10]$. Ademais, baixa densidade de carga e dificuldades de coleta e manuseio de biomassas lenhosas podem ser fatores limitantes para seu uso em grande escala em coquerias [2].

Tabela 1. Análise granulométrica do carvão vegetal

\begin{tabular}{|c|c|c|c|c|c|c|}
\hline $\begin{array}{c}\text { Distribuição } \\
\text { Granulométrica }\end{array}$ & $>4,0 \mathrm{~mm}$ & $>2,83 \mathrm{~mm}$ & $>1,4 \mathrm{~mm}$ & $>1,0 \mathrm{~mm}$ & $>0,5 \mathrm{~mm}$ & $<0,5 \mathrm{~mm}$ \\
\hline Fração F (\%) & - & - & 11,28 & 7,63 & 18,87 & 62,22 \\
\hline Fração G (\%) & 29,88 & 35,53 & 22,10 & 0,23 & 0,78 & 11,48 \\
\hline
\end{tabular}

Com base nos resultados, é possível observar que a fração $\mathrm{F}$ é constituída por $81 \%$ de partículas menores que $1 \mathrm{~mm}$ e que a fração $\mathrm{G}$ apresenta $87 \%$ de partículas maiores que $1 \mathrm{~mm}$.

As principais características da mistura de carvões e das frações granulométricas de carvão vegetal utilizadas são apresentadas na Tabela 2.

Tabela 2. Caracterização química das matérias-primas

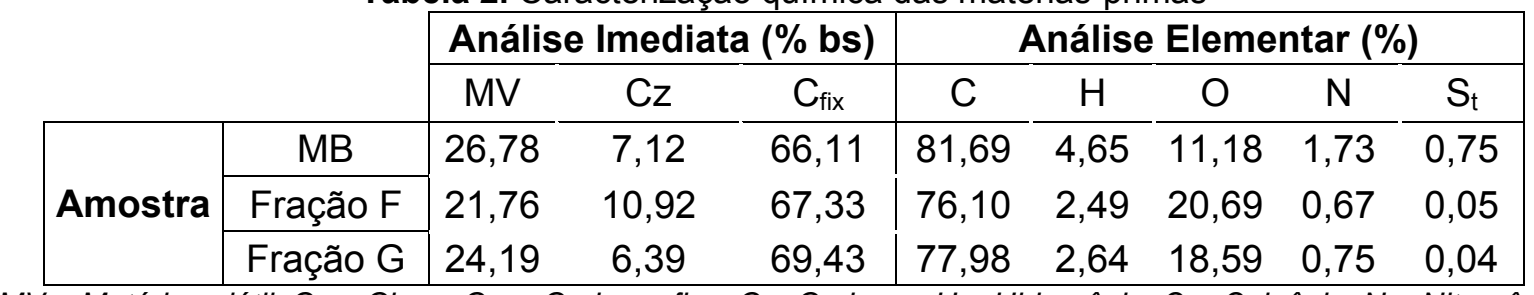

$M V=$ Matéria volátil; $C z$ = Cinza; $C_{f i x}=$ Carbono fixo; $C=$ Carbono; $H$ = Hidrogênio; $O=$ Oxigênio; $N$ = Nitrogênio; $S_{t}=$ Enxofre total; $b s=$ Base seca. 
Através das análises químicas das matérias-primas, pode-se observar que a fração $\mathrm{F}$ de carvão vegetal, composta predominantemente por partículas menores, apresentou um teor de cinza quase $70 \%$ maior que a fração G. Essa grande diferença pode estar relacionada ao manuseio industrial do carvão vegetal na fração $F$, uma vez que a suceptibilidade a contaminações de natureza exógena é mais elevada em materiais que contêm maiores quantidades de partículas finas.

A quantidade de matéria volátil presente na fração $G$ e o teor de carbono fixo foram superiores aos notados na fração $F$. Biomassas apresentam composições químicas distintas devido a sua alta variação de umidade, cinzas produzidas e os diferentes tipos genéticos de matéria inorgânica presentes [11]. Os teores de enxofre total das duas frações de carvão vegetal são praticamente iguais; contudo, muito inferiores ao da mistura base de carvões MB utilizada.

O resultado da análise de refletância da vitrinita pode ser visto no reflectograma da Figura 2, na qual o eixo das ordenadas apresenta a frequência percentual de cada um dos subgrupos observados.

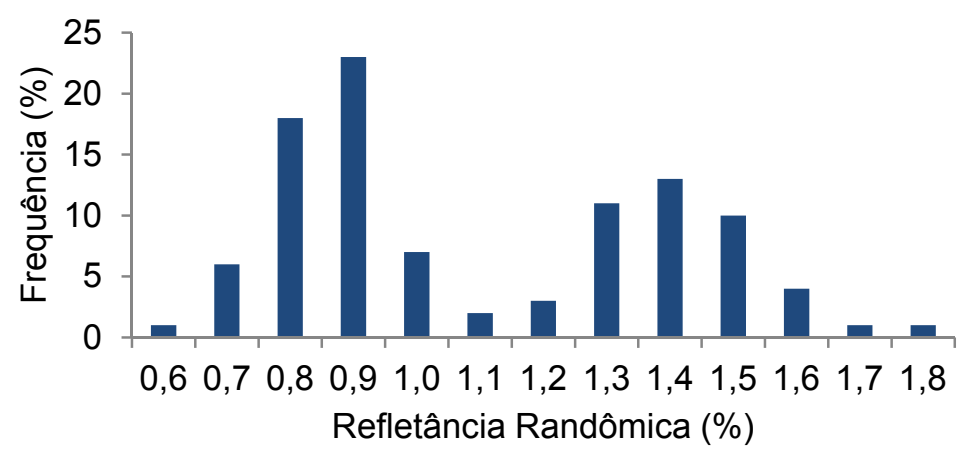

Figura 2. Análise de refletância da vitrinita da mistura de carvões MB.

\subsection{Caracterização dos Coques}

Os resultados obtidos através da análise imediata e de enxofre total das sete amostras de coques produzidas são apresentados na Tabela 3 . Todos os coques analisados se encontram dentro da maioria das faixas de especificações químicas adotadas atualmente para uso em altos-fornos [12].

Tabela 3. Análise imediata e de enxofre total dos coques

\begin{tabular}{|c|c|c|c|c|c|c|c|c|}
\cline { 2 - 8 } \multicolumn{2}{c|}{} & \multicolumn{7}{|c|}{ Amostra } \\
\cline { 2 - 9 } \multicolumn{2}{c|}{} & CMB & CF3 & CF5 & CF10 & CG3 & CG5 & CG10 \\
\hline \multirow{3}{*}{ Análise Imediata (\% bs) } & MV & 1,20 & 1,40 & 1,33 & 1,68 & 1,37 & 1,39 & 1,67 \\
\cline { 2 - 9 } & Cz & 9,66 & 9,21 & 9,44 & 10,05 & 9,46 & 9,69 & 9,63 \\
& $\mathrm{C}_{\mathrm{fix}}$ & 89,13 & 89,39 & 89,24 & 88,27 & 89,18 & 88,93 & 88,70 \\
\hline Enxofre (\%) & $\mathrm{S}_{\mathrm{t}}$ & 0,630 & 0,657 & 0,628 & 0,606 & 0,638 & 0,615 & 0,578 \\
\hline
\end{tabular}

$M V=$ Matéria volátil; $C \mathrm{Cz}=$ Cinza; $C_{f i x}=$ Carbono fixo; $S_{t}=$ Enxofre total; bs = Base seca.

A partir dos resultados, é possível verificar que o teor de matéria volátil dos coques, em base seca, ficou na faixa de $1,20 \%$ a $1,68 \%$. A quantidade de matéria volátil foi superior apenas nas amostras de coque com teor de adição de carvão vegetal de $10 \%$ (CF10 e CG10) visto que as demais amostras encontram-se dentro do mesmo limite de repetibilidade da análise.

Com relação ao teor de cinzas, os coques elaborados com a adição da fração $G$ mantiveram seus teores de cinza muito próximos aos do coque CMB. Isso possivelmente está relacionado ao fato de o teor de cinza da fração $G$ ser próximo 
ao da mistura base de carvões (Tabela 2). Já a incorporação da fração $\mathrm{F}$, em teores de $3 \%$ e $5 \%$, não aumentou o teor de cinza dos coques em relação ao coque CMB, embora essa fração contivesse $70 \%$ a mais de cinzas que a fração $\mathrm{G}$. O aumento na quantidade de cinza dos coques somente foi observado de maneira pronunciada no coque feito com $10 \%$ de adição de carvão vegetal na fração $F$ (CF10).

Em relação aos teores de enxofre total, não houve queda significativa na quantidade de enxofre total encontrada no coque $\mathrm{CMB}$ em relação às quantidades de carvão vegetal que foram agregadas, à exceção de CG10, que teve um teor $8 \%$ inferior ao $\mathrm{CMB}$. Também foi observado um valor superior à quantidade de enxofre total de CMB no coque CF3. Da Silva [3], ao adicionar $6 \%$ de biomassa de casca de arroz calcinada a um carvão médio volátil, conseguiu observar em escala industrial uma queda bem maior no teor de enxofre em relação a um enfornamento não contendo biomassa.

Os principais efeitos da adição de carvão vegetal na reatividade (CRI) dos coques são apresentados no gráfico da Figura 3, à exceção da amostra de coque produzido com a fração $\mathrm{F}$ e contendo $10 \%$ de carvão vegetal.

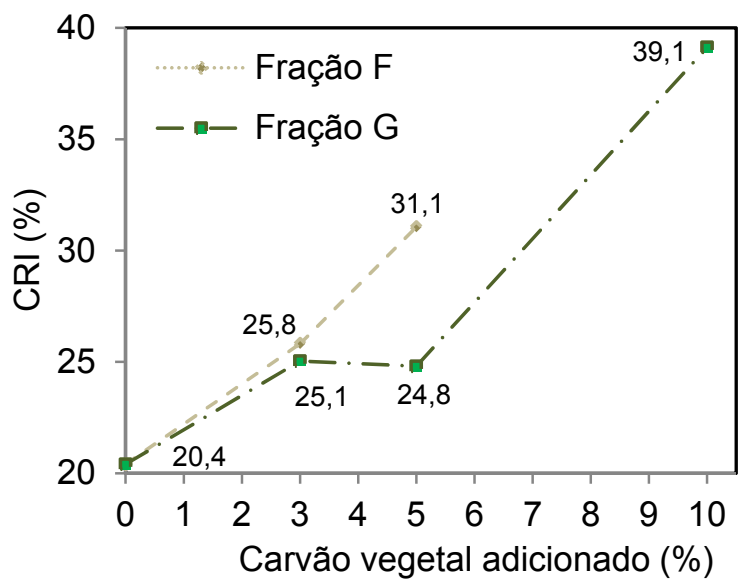

Figura 3. Influência da incorporação de carvão vegetal na reatividade.

De maneira geral, a adição de carvão vegetal causou um aumento da reatividade dos coques produzidos com ambas granulometrias, e o impacto dessa adição foi semelhante apenas para o teor de $3 \%$ de carvão vegetal incorporado. $O$ aumento do teor de carvão vegetal de $3 \%$ para $5 \%$ somente resultou em um acréscimo na reatividade do coque gerado com a fração $F$, visto que os valores observados para a fração $\mathrm{G}$ (25,1 e 24,8 respectivamente) estão dentro do limite de repetibilidade para análises de CRI sem repetição e, portanto, são considerados equivalentes. Além disso, o coque elaborado com $10 \%$ de carvão vegetal na fração $G$ teve um valor de $\mathrm{CRI}$ quase duas vezes superior ao coque referência (CMB). A correlação entre os valores de CRI e CSR verificados para os sete coques (exceto CF10) apresentou um coeficiente de determinação $\left(R^{2}\right)$ de 0,95 . Mac Phee e outros autores sugerem que uma das possibilidades para o aumento da reatividade pode ser explicada pelo alto teor de alguns constituintes da matéria mineral, como óxidos de cálcio e ferro $[4,13]$. Os efeitos da adição de carvão vegetal na qualidade do coque, em termos de resistência mecânica a frio (DI) e a quente (CSR), também estão representados nos gráficos da Figura 4 (a) (Fração F) e Figura 4 (b) (Fração G), à exceção do CSR do coque produzido com a fração $\mathrm{F}$ e contendo $10 \%$ de carvão vegetal, o CF10. 

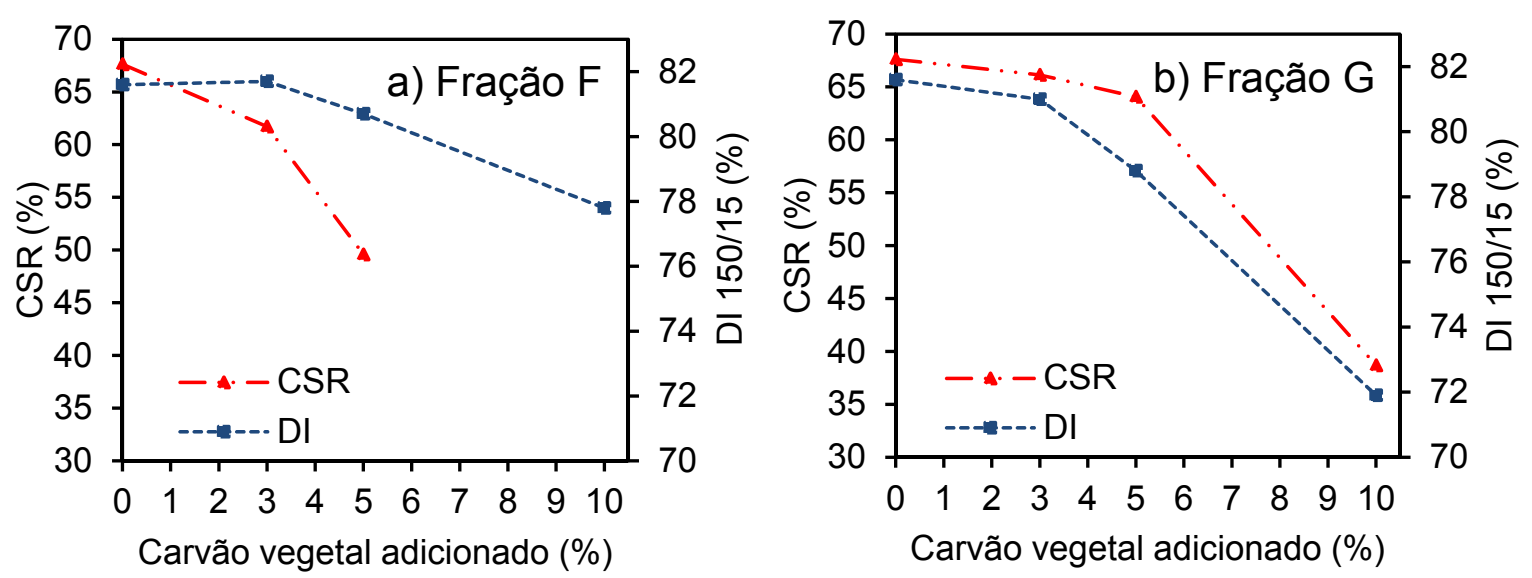

Figura 4. Influência da incorporação de carvão vegetal em diferentes composições granulométricas na qualidade do coque: a) Fração F; b) Fração G.

$\mathrm{Na}$ Figura 4 (a), é possível observar que os coques produzidos com adição de $3 \%$ e $5 \%$ de carvão vegetal na fração $F$ não sofreram alteração em sua resistência mecânica a frio (DI) quando equiparados à amostra de referência, sem carvão vegetal adicionado. Os valores de DI 150/15 verificados nessas três amostras estão dentro do mesmo intervalo de tolerância. Somente a inclusão de $10 \%$ de carvão vegetal acarretou em uma queda na resistência dos coques preparados com a fração $\mathrm{F}$ acrescentada. Diferentemente do $\mathrm{DI}$, os valores de CSR para adições de $3 \%$ e $5 \%$ de carvão vegetal promoveram alterações significativas em relação ao coque sem carvão vegetal. A introdução de $5 \%$ de carvão vegetal diminui o CSR do coque de maneira muito pronunciada.

As alterações de resistência mecânica a frio dos coques produzidos com a fração $G$ foram bem mais pronunciadas em comparação à fração $\mathrm{F}$. Esse comportamento também foi verificado por Montiano [5], que observou uma queda menos pronunciada no DI 150/15 de coques feitos com a adição de resíduo de pinheiro contendo maior percentual de partículas inferiores a $0,5 \mathrm{~mm}$. Segundo Gray [14], inertes orgânicos e inorgânicos, com tamanho de partícula de 2 a $4 \mathrm{~mm}$, agem como núcleos de fissuração do coque, pois apresentam uma fraca ligação estrutural quando adicionados ao coque. $\mathrm{O}$ aumento do teor de carvão vegetal na fração $\mathrm{G}$ Figura 4 (b) - trouxe uma queda no DI já na amostra com $5 \%$ de carvão vegetal, e essa queda foi ainda maior para o coque com $10 \%$ de carvão vegetal. Esse mesmo comportamento também foi observado no CSR dos coques com a fração $G$ incorporada. Além disso, pode-se afirmar que a adição de $3 \%$ de carvão vegetal não provocou alteração na resistência mecânica a quente quando equiparada à amostra sem carvão vegetal, posto que ambos os valores de CSR encontram-se dentro do mesmo limite de repetibilidade do teste. Confrontando os valores de CSR da fração $F$ e da fração $G$ dos coques com $5 \%$ de carvão vegetal, é possível notar uma redução menos pronunciada para a fração $\mathrm{G}$, indicando que a incorporação até essa quantidade não afeta relevantemente a resistência a quente dos coques elaborados com a fração G. A Figura 5 apresenta uma ilustração da adesão do carvão vegetal à matriz carbonosa do coque com aumento de 500 vezes das amostras de coque produzidas com adição de carvão vegetal na fração G. 


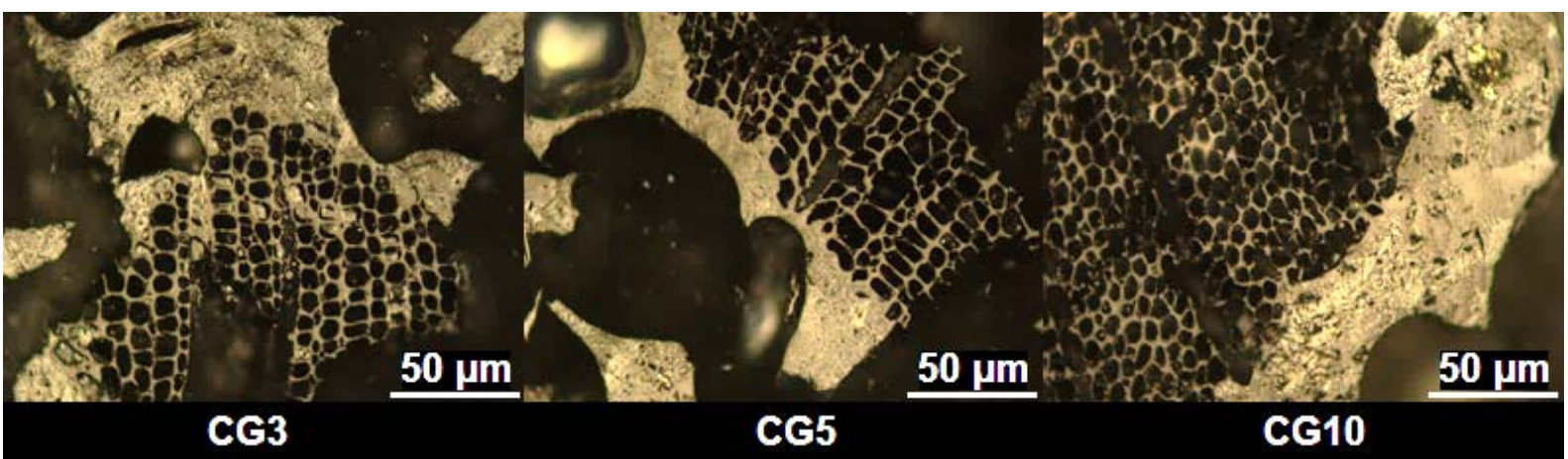

Figura 5. Microestrutura dos coques produzidos com a adição da fração $\mathrm{G}$.

Ueki avaliou por imagens a macroestrutura de coques produzidos com adição de biomassa e sugeriu que a adesão estrutural entre coque e biomassa poderia ser maior caso a biomassa passasse por um tratamento térmico prévio para remoção de seus voláteis [6].

A Tabela 4 apresenta os resultados das análises petrográficas realizadas nas sete amostras de coque em percentual volumétrico, segundo a classificação adotada e adaptada. Algumas texturas como isotrópica e banda grossa não foram observadas nas amostras analisadas e, por isso, foram excluídas da tabela.

Tabela 4. Análise petrográfica dos coques

\begin{tabular}{|c|c|c|c|c|c|c|c|c|}
\hline & \multicolumn{7}{|c|}{ Amostra } \\
\hline & & $\mathrm{CMB}$ & CF3 & CF5 & CF10 & CG3 & CG5 & CG10 \\
\hline \multirow{9}{*}{ Matriz (\% vol.) } & Inc & 0,42 & - & 0,24 & 0,80 & 0,22 & 0,60 & 1,00 \\
\hline & $M_{f}$ & 5,93 & 8,20 & 6,87 & 11,60 & 13,88 & 14,00 & 15,00 \\
\hline & $\mathrm{M}_{\mathrm{m}}$ & 7,84 & 9,40 & 8,77 & 9,40 & 13,23 & 8,40 & 9,20 \\
\hline & $\mathrm{Mg}_{\mathrm{g}}$ & 0,42 & 4,20 & 2,13 & 0,60 & 1,52 & 1,40 & 0,60 \\
\hline & $L_{f}$ & 22,03 & 24,40 & 21,80 & 18,20 & 22,56 & 24,80 & 21,60 \\
\hline & $L_{m}$ & 14,41 & $\mid 10,00$ & 12,56 & 6,20 & 2,82 & 6,60 & 6,00 \\
\hline & $\mathrm{Lg}_{\mathrm{g}}$ & - & - & 0,95 & 0,20 & - & - & - \\
\hline & $B_{f}$ & 16,74 & 9,80 & 12,80 & 11,60 & 14,53 & 11,60 & 12,80 \\
\hline & $\mathrm{B}_{\mathrm{m}}$ & - & - & - & 0,20 & - & - & - \\
\hline Inertes Orgânicos (\% vol.) & $F+G$ & 22,25 & 20,40 & 24,87 & 30,20 & 24,73 & 23,40 & 24,20 \\
\hline Inertes Inorgânicos (\% vol.) & MM & 2,12 & 2,00 & 1,18 & 1,60 & 0,87 & 1,20 & 0,40 \\
\hline Depósitos de Carbono (\% vol.) & PIR & 0,85 & 0,40 & 0,24 & 0,20 & 0,22 & - & 0,80 \\
\hline Aditivos Carbonosos (\% vol.) & PET & 6,99 & 11,20 & 7,58 & 9,20 & 5,42 & 8,00 & 8,40 \\
\hline
\end{tabular}

A partir dos dados, é possível observar que a adição de 3\% de carvão vegetal (CF3 e CG3) à mistura base, em relação ao coque CMB, causou um aumento mais pronunciado de texturas do tipo mosaico que os coques produzidos com teores de 5 e $10 \%$ de carvão vegetal. De maneira oposta, a adição de $3 \%$ de carvão vegetal na fração $G$ impactou em uma grande diminuição no percentual volumétrico de texturas do tipo lenticular, enquanto as amostras com teores de 5\% e 10\% (CG5 e CG10) tiveram uma queda mais moderada desse tipo de textura. Texturas do tipo 
mosaico são provenientes de carvões coqueificáveis alto voláteis enquanto texturas do tipo lenticular são originárias de carvões médio voláteis [15].

Para os coques produzidos com a fração $F$, a adição de $3 \%$ e $5 \%$ de carvão vegetal não variou a quantidade de texturas lenticulares de forma notável, somente a incorporação de $10 \%$ promoveu uma redução nesse tipo de textura comparado a $\mathrm{CMB}$. Em relação à textura do tipo banda, foi verificado que todos os coques com carvão vegetal tiveram um percentual volumétrico inferior à amostra referência CMB. A quantidade volumétrica dessas texturas foi menor para as amostras CF3 (dos coques com incorporação da fração F) e CG5 (dos coques preparados com a fração $G$ ).

As amostras CF5 e CF10 tiveram um aumento de seus percentuais de inertes orgânicos bem mais consideráveis quando comparadas às amostras feitar com a fração G, CG5 e CG10. A quantidade de inertes orgânicos entre os coques variou de $0,40 \%$ a $2,12 \%$ e de coque de petróleo entre $5,42 \%$ a $11,20 \%$.

\section{CONCLUSÕES}

Os resultados obtidos no estudo da incorporação de carvão vegetal em mistura de carvões para coqueificação em forno piloto permitiram chegar às seguintes conclusões:

- A mescla, contendo a mistura base de carvões e carvão vegetal, que produziu o coque com melhor qualidade em termos de CRI/CSR e DI foi a com adição de $3 \%$ de carvão vegetal na fração $G$, porém pôde-se observar que a adição de até $5 \%$ da mesma fração é possível sem comprometer a qualidade do coque;

- Os coques elaborados com incorporação de carvão vegetal na fração F tiveram menor qualidade em termos de CRI/CSR e maior resistência mecânica a frio quando comparados aos coques feitos com a incorporação da fração $G$;

- A inserção de carvão vegetal na mistura base escolhida não trouxe uma queda significativa no teor de enxofre dos coques, à exceção da amostra CG10 que teve uma redução de aproximadamente $8 \%$ em comparação ao coque de referência $\mathrm{CMB}$;

- De maneira geral, os coques feitos com adição de carvão vegetal na fração F e na fração $G$, em relação à amostra produzida sem carvão vegetal $C M B$, tiveram um aumento do seu percentual volumétrico de texturas do tipo mosaico e uma redução das texturas do tipo lenticular e bandas.

\section{Agradecimentos}

Agradecemos a Gerdau Usina de Ouro Branco pelo suporte e parte da execução deste trabalho, ao Conselho Nacional de Desenvolvimento Científico e Tecnológico (CNPq) pela bolsa de estudo (processo 132958/2014-7), ao Programa de PósGraduação em Engenharia de Minas, Metalúrgica e Materiais (PPGE3M) da Escola de Engenharia da Universidade Federal do Rio Grande do Sul e ao Instituto Nacional del Carbón (INCAR) - Espanha - pela ajuda científica e cooperação neste trabalho.

\section{REFERÊNCIAS}

1 Instituto Aço Brasil. Anuário Estatístico. Rio de Janeiro: 2014.

2 Matsumura T, Ichida M, Nagasaka T, Kato K. Carbonization behavior of woody biomass and resulting metallurgical coke properties. ISIJ Internacional. 2008;(48):572-577. 
3 Da Silva AM, Bentes MA, Medrado SB, Sobrinho PM, Carvalho Júnior JÁ. Estudo da utilização da biomassa em substituição parcial ao carvão mineral na fabricação do coque na coqueria da CSN. Tecnologia em Metalurgia e Materiais. 2008;(5):40-45.

4 MacPhee JA, Gransden JF, Giroux L, Price JT. Possible $\mathrm{CO}_{2}$ mitigation via addition of charcoal to coking coal blends. Fuel Processing Technology. 2009;(90):16-20.

5 Montiano MG, Díaz-Faes E, Barriocanal C, Alvarez R. Influence of biomass on metallurgical coke quality. Fuel. 2014;(116):175-182.

6 Ueki Y, Nunome Y, Yoshile R, Naruse I, Nishibata Y, Aizawa S. Effect of woody biomass addition on coke properties. ISIJ Internacional. 2014:54(11):2454-2460.

7 Flores BD, Flores IV, Orellana DR, Pohlmann JG, Barbieri CT, Zymla V, Osório E, Vilela ACF. Carvão vegetal como aditivo para coqueificação: estudo da reatividade ao $\mathrm{CO}_{2 .} 44^{\circ}$ Seminário de Redução de Minério de Ferro e Tecnologia Mineral. 2014;554568.

8 Instituto Aço Brasil. Relatório de Sustentabilidade. 2014. [acesso em 9 de abr. de 2015]. 1-96. Disponível em:

http://www.acobrasil.org.br/site/portugues/biblioteca/Relatorio\%20de\%20Sustentabilida de_2014_web.pdf

9 Kaye JC, Horton AE. Composition and preparation of blends for making metallurgical coke. Commission of the European communities. 1975;35-44.

10 Loison R, Foch P, Boyer A. COKE Quality and Production. $2^{\mathrm{a}}$ edição. Londres: Butterworths; 1989.

11 Vassilev SV, Baxter D, Andersen LK, Vassileva CG. An overview of the composition and application of biomass ash. Part 1. Phase-mineral and chemical composition and classification. FUEL. 2013;(105):40-76.

12 Gulyaev VM, Barskii VD, Rudnitskii AG. European quality requirements on blast-furnace coke. Coke and Chemistry. 2012;(55):372-376.

13 Díez MA, Borrego AG. Evaluation of $\mathrm{CO}_{2}$ reactivity patterns in cokes from coal and woody biomass blends. Fuel. 2013;(113):59-68.

14 Gray RJ. Some applications to coal, coke and carbons. Organic Geochemistry. 1991;(17):535-555.

15 Gray RJ, Devanney KF. Coke carbon forms: microscopic classification and industrial applications. 1986;(6):277-297. 